\title{
The Effect of Hydro-Alcoholic Extract of Rosa damascena on Uterine Constriction of Virgin Rats
}

\author{
Morteza IsaAbadi Bozcheloei, ${ }^{1,2}$ Musa Ghazikhanloo Sani, ${ }^{1,2}$ Katayoun Sedaghat, ${ }^{1}$ Morteza Jarrahi, ${ }^{1}$ \\ Hanieh Nejat, ${ }^{1,2}$ and Mahdi Zahedi Khorasani ${ }^{1,}$ \\ ${ }^{1}$ Research Center and Department of Physiology, Faculty of Medicine, Semnan University of Medical Sciences, Semnan, Iran \\ ${ }^{2}$ Students Research Committee, Semnan University of Medical Sciences, Semnan, Iran \\ "Corresponding author: Mahdi Zahedi Khorasani, Research Center and Department of Physiology, Faculty of Medicine, Semnan University of Medical Sciences, Km 5 of \\ Damquan road, Semnan, Iran. Tel: +98-23333654218, E-mail: zahedikhorasani@yahoo.com \\ Received 2017 May 13; Accepted 2017 May 16.
}

\begin{abstract}
Background: Few studies have evaluated the effect of Rosa damascena (R. damascena) on uterine smooth muscle contraction and dysmenorrhea; but, their results were inconsistent.

Objectives: The aim of the study was to consider the effect of alcoholic extract of $R$. damascena flower on uterine smooth muscle contraction amplitude, duration, and frequency in virgin rats.

Methods: Thirty adult Wistar rats (180 - 220 g) were randomly divided into 3 groups including control, extract, and oxytocin plus extract. After anesthesia, $1.5 \mathrm{~cm}$ of the uterine horn was cut and placed in an organ bath. The contractile responses of the uterine smooth muscle to a cumulative concentration of alcoholic extract of $R$. damascena flower $(1,2$, and $4 \mathrm{mg} / \mathrm{mL}$ ) and to oxytocin (4 $\mathrm{mU} / \mathrm{mL}$ ) plus alcoholic extract of $R$. damascena were recorded. The extract or oxytocin was diluted in $0.2 \mathrm{ml}$ of De Jalon solution and added to the organ bath. The amplitude, duration, and interval of contractions were recorded.

Results: The alcoholic extract of $R$. damascena $(4 \mathrm{mg} / \mathrm{mL})$ significantly reduced the basal contractions of uterine smooth muscle (P $=0.004)$. Rosa damascena $(4 \mathrm{mg} / \mathrm{mL})$ significantly diminished oxytocin-induced uterine smooth muscle contractions $(\mathrm{P}=0.026)$. The extract of $R$. damascena had no significant effect on the duration of normal or oxytocin-induced contractions in uterine smooth muscle. However, $R$. damascena $(4 \mathrm{mg} / \mathrm{mL})$ significantly reduced the frequency of uterine contraction in normal $(\mathrm{P}=0.006)$ and oxytocin-induced contractions $(\mathrm{P}=0.014)$.

Conclusions: Rosa damascena extract reduced the amplitude and frequency of the basal and oxytocin-induced contractions in the uterine smooth muscle of virgin rats. The extract may relieve dysmenorrhea and premature labor, which needs further study for more clarification.
\end{abstract}

Keywords: Extract, Contraction, Uterine, Rats, Rosa

\section{Background}

The smooth muscles have great importance in medicine as they are involved in many diseases including asthma, hypertension, dysmenorrhea, and gastrointestinal disorders. They are the major target of phytotherapy and related studies. Today, medical herb is considered for treatment of many diseases as they have a few side effects compared to chemical drugs (1). Nevertheless, medicinal herbs also may have side or even toxic effects, so they must be used with caution (2). Damask rose with a scientific name of Rosa damascena (R. damascena) is one of the beneficial plants used in traditional medicine. It has different pharmacological effects including hypnotic, anticonvulsant, anti-depressant, antianxiety, analgesic, nerve growth-promoting, and sedative effects (3-7). In addition, its effect on reduction of blood pressure and breathing rate has been mentioned in previous studies. Other stud- ies have reported antimicrobial and antioxidant effects of the plants $(8,9)$.

Effects of $R$. damascena have been reported previously on the respiratory system, as the inhalation of Rosa extract has been shown to reduce the number of coughs in guinea pigs (10). Tracheal smooth muscle contraction induced by methacholine or potassium chloride in the guinea pigs reduced with the use of hydro-alcoholic extract of Rosa flowers, indicating its dilation effect on respiratory tract (11). Also, a potent relaxant effect for ethyl acetate fraction of $R$. damascena (but a relatively weak relaxant effect for aqueous and n-butanol fractions) on tracheal smooth muscles has been shown, which was comparable to the theophylline effect (12). A combination has been taken from flower bud (known as cyanidin-3-O- $\beta$ - glucoside) inhibiting the angiotensin-converting enzyme (13). In addition, $R$. damascena extract at microgram concentrations could show the stimulatory effect on ileum smooth mus- 
cles while at milligram concentrations, it showed an inhibitory effect. This displays the presence of different components in the extract (14).

Dysmenorrhea is a cyclic pain that affects many females in their menstrual cycle. The primary dysmenorrhea frequently begins with ovulation and usually causes severe pain and social problems like individual's absence from daily activities. Thus, research to better understand and treat dysmenorrhea has a high priority of study. In a recent study, the effect of ethanol extracts of $R$. damascena leaves has been studied on the trachea, aortic, and uterine smooth muscles of rats. The results showed contractile effects of the plant extract on all types of smooth muscle (15, 16). That is somewhat in contrast to earlier findings. Moreover, in a new study, the effect of $R$. damascena extract was studied on primary dysmenorrhea in 92 girls showing that the dietary extract of $R$. damascena and Mefenamic acid had similar effects on pain intensity of primary dysmenorrhea (17). R. damascena and its products like rose water are commonly used as air freshener and flavors. There are limited studies on $R$. damascena effect on uterine smooth muscle contraction and dysmenorrhea with inconsistent results.

\section{Objectives}

To gain a better understanding of the effect of $R$. damascena on uterine smooth muscle contraction, this study was performed to examine the effect of alcoholic extract of $R$. damascena on amplitude, duration, and frequency of basal and oxytocin-induced contraction in uterine of virgin rats.

\section{Methods}

\subsection{Laboratory Animals}

In this experimental study, 30 virgin female Wistar rats (180 - $220 \mathrm{~g}$ ) were prepared from animal house of Semnan University of Medical Sciences, Semnan, Iran. The animals were housed in individual cages in a 12-h light/dark cycle at $22-24^{\circ} \mathrm{C}$, with food and water available ad libitum. The experimental protocol was approved by the ethics review board of Semnan University of Medical Sciences. All the experimental trials were conducted in agreement with the national institutes of health guide for care and use of laboratory animals.

\subsection{Experimental Groups}

The 30 female Wistar rats were randomly divided into 3 experimental groups with equal members as follows:

In group one named the control group $(n=10)$, the effect of the vehicle of extract or oxytocin on the variables of smooth muscle contraction including tension, duration, and frequency of contraction was recorded.

In group two or the extract group $(n=10)$, the effect of cumulative $R$. damascena $(1,2$, and $4 \mathrm{mg} / \mathrm{mL})$ on the uterine horn contraction was measured.

In group three $(\mathrm{n}=10)$, the effects of oxytocin ( 4 $\mathrm{mU} / \mathrm{mL}$ ) and subsequently $R$. damascena $(1,2$, and $4 \mathrm{mg} / \mathrm{mL})$ on the uterine horn contraction were recorded. The flow chart of the study is illustrated as following:

\subsection{Preparation of rat Uterine Horn and Recording Isometric Contraction}

The female rats were anesthetized with thiopental sodium ( $80 \mathrm{mg} / \mathrm{kg}$, IP, Kwality Pharmaceutical Pvt. Ltd. India). The inferior lateral part of the abdomen was opened and a segment of the uterine horn was dissected and placed in Petri dishes containing cold $\left(4^{\circ} \mathrm{C}\right)$ De Jalon solution. The composition of De Jalon solution in $\mathrm{mmol} / \mathrm{L}$ was: $\mathrm{NaCl}: 154, \mathrm{KCl} ; 5.63, \mathrm{CaCl}_{2}: 0.64, \mathrm{NaHCO}_{3}: 5.95$, and Glucose: 2.77 (all purchased from Sigma-Aldrich), pH: 7.4 and temperature: $36 \pm 1^{\circ} \mathrm{C}$ ). Then, the uterine horn segment (about $15 \mathrm{~mm}$ ) was attached to an isometric force transducer (F60, Narco Bio Systems, USA) coupled to the physiograph (Narco Bio Systems, USA) for contraction recording. Organ bath (Double Tissue Bath-Harvard) containing De Jalon solution was constantly gassed with $95 \% \mathrm{O}_{2}$ and $5 \% \mathrm{CO}_{2}$ and renewed every 15 minutes. The uterine horn segments were placed under $1.0 \mathrm{~g}$ resting tension for 60 minutes to reach the equilibrium. Uterine horns responses to vehicle, alcoholic extracts of $R$. damascena flower with the cumulative concentrations of 1,2 , and $4 \mathrm{mg} / \mathrm{mL}$, or oxytocin $(4 \mathrm{mU} / \mathrm{mL})$ followed by alcoholic extracts of $R$. damascena flower were recorded in different groups. Oxytocin was prepared in the form of ampoule from Caspian Tamin pharmaceutical Co., Iran. For vehicle preparation, the ampoules were boiled for half an hour in order to damage the oxytocin peptide.

\subsection{Measurement of Contraction Variability}

Uterine horns responses to the vehicle of extract or oxytocin were recorded. The physiograph was calibrated before any recording as follows: the sensitivity of instrument changed to the level that $1 \mathrm{~g}$ load moved up recording pen $25 \mathrm{~mm}$. Amplitude or tension of contraction was measured as the pen displacement compared to calibrated size. As the speed of recording paper was $0.05 \mathrm{~cm} / \mathrm{s}$, the duration or interval of contraction was calculated by measuring the length of contraction wave (duration) or the length between two contractions. 


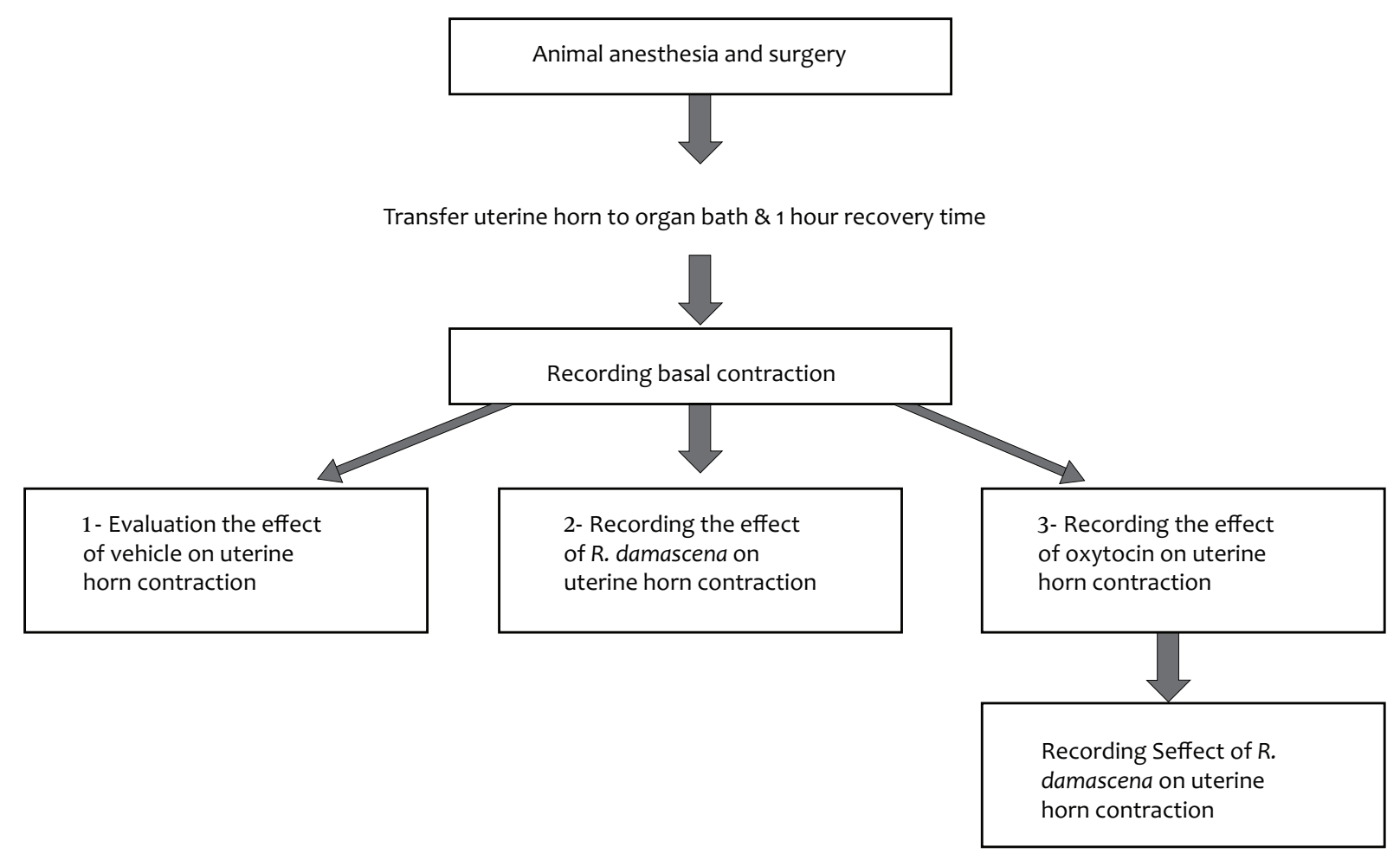

Figure 1. The Flow Chart of the Study

\subsection{Plant and Extract Preparation}

The plant $R$. damascena was obtained from the organization of promotion, education, and agricultural research center, Semnan, in summer 2015. The flowers of R. damascena were dried in shadow, ground, and its hydroalcoholic extract was prepared by soxhlet apparatus via repeated distillation methods in 12 hours. The solution was then filtered and dried in oven at $40^{\circ} \mathrm{C}$ and finally stored at $4{ }^{\circ} \mathrm{C}$.

\subsection{Statistical Analysis}

The results were presented as mean \pm standard error of the mean (SEM); the criteria for statistical significance was $\mathrm{P}<0.05$. The between-groups differences were analyzed using paired or unpaired Student's t-test or repeated measures ANOVA for multiple comparisons (SigmaStat.3.0Germany).

\section{Results}

4.1. The Effect of R. damascena on the Uterine Smooth Muscle Contraction in the Absence or Presence of Oxytocin

At first, basal smooth muscle contractions of the isolated virgin uterine horn were recorded. Then, either vehicle or alcoholic extract of $R$. damascena was added to the organ bath in stepwise increasing concentrations of 1,2 , and $4 \mathrm{mg} / \mathrm{mL}$ with 1-minute intervals. Vehicle and lower concentrations of the extract had not significant effects on the basal uterine contractions; however, $R$. damascena ( $4 \mathrm{mg} / \mathrm{mL}$ ) reduced uterine contraction significantly compared to the base and lower concentrations of the extract $(\mathrm{P}=0.004$, Figure 2$)$.

Figure 2. The Effect of R. damascena on the Basal Uterine Contractions

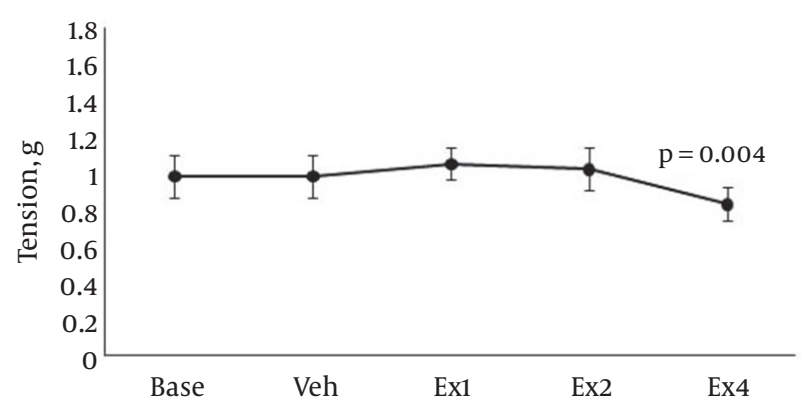

R. damascena $(4 \mathrm{mg} / \mathrm{mL})$ reduced uterine contraction significantly. Veh: vehicle, Ex1, Ex2, and Ex4 are the $R$. damascena extracts with the concentration of 1, 2, and $4 \mathrm{mg} / \mathrm{mL}, \mathrm{P}=0.004$ compare to other groups. 
In the oxytocin group, the vehicle of oxytocin had no significant effect on the basal uterine smooth muscle contractions, but oxytocin $(4 \mathrm{mU} / \mathrm{mL})$ increased uterine contractions significantly from $0.91 \mathrm{~g}$ to $1.49 \mathrm{~g}(\mathrm{P}=0.001$, Figure 2). Then, the cumulative extract of $R$. damascena was added to the organ bath in stepwise increasing concentrations: 1 , 2 , and $4 \mathrm{mg} / \mathrm{mL}$; $R$. damascena $(4 \mathrm{mg} / \mathrm{mL})$ reduced uterine contractions induced by oxytocin $(\mathrm{P}=0.026$, Figure 3$)$.

Figure 3. The Effect of R. damascena on the Oxytocin-Induced Contractions in Uterine Horn

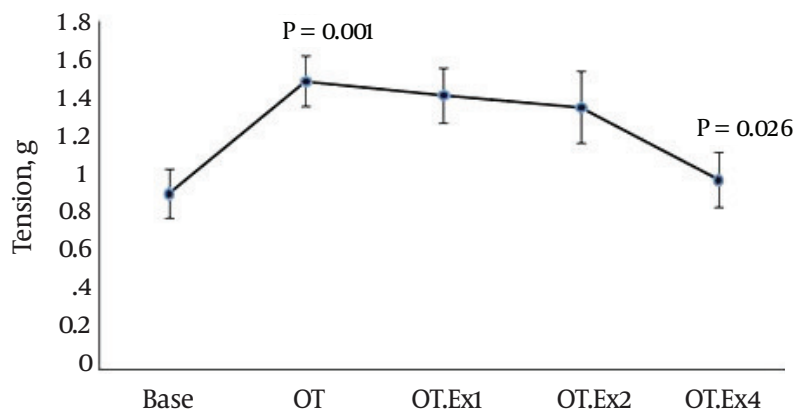

Oxytocin increased uterine contraction while it reduced significantly by R. damascena $(4 \mathrm{mg} / \mathrm{mL})$. OT: oxytocin, OT.Ex1, OT.Ex2, and OT.Ex4 are the oxytocin plus R. damascena with concentrations of 1,2 and $4 \mathrm{mg} / \mathrm{mL}$, respectively. $\mathrm{P}=0.001$ compared to base and $\mathrm{P}=0.026$ compared to oxytocin.

4.2. The Effect of R. damascena Extracts on the Uterine Smooth Muscle Contraction Interval in the Absence or Presence of Oxytocin

Initially, basal frequency (reverse of the interval) of uterine smooth muscle contractions was recorded. Then, either vehicle or alcoholic extracts of $R$. damascena was added to the organ bath in stepwise increasing concentrations 1,2 and $4 \mathrm{mg} / \mathrm{mL}$ with 1-minute intervals. Vehicle and lower concentrations of the extract had no significant effects on the basal frequency of contractions while R. damascena extract at $4 \mathrm{mg} / \mathrm{mL}$ concentration significantly reduced the frequency of contraction compared to the base and extract $1(\mathrm{P}=0.006$, Figure 4$)$.

The vehicle of oxytocin had no significant effect on the basal frequency (reverse of the interval) of uterine contraction, but oxytocin $(4 \mathrm{mU} / \mathrm{mL})$ increased the frequency of contractions significantly. Then, cumulative concentrations of $R$. damascena extract were added to the organ bath in stepwise increasing concentrations of 1,2 and $4 \mathrm{mg} / \mathrm{mL}$; R. damascena ( 2 and $4 \mathrm{mg} / \mathrm{mL}$ ) could reduce the frequency of uterine contractions significantly (Figure 5).
Figure 4. The Effect of $R$. damascena on the Uterine Contractions Interval (Frequency) at a Basal Level

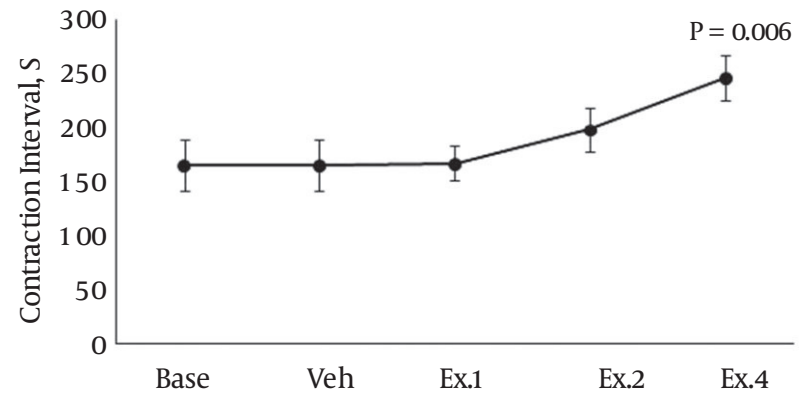

R. damascena $(4 \mathrm{mg} / \mathrm{mL})$ reduced the frequency of uterine contraction significantly. Veh: vehicle, Ex.1, Ex.2, and Ex.4 are the R. damascena extracts with the concentration of 1,2 and $4 \mathrm{mg} / \mathrm{mL}, \mathrm{P}=0.006$ compared to base.

Figure 5. The Effect of R. damascena on the Interval (Frequency) of Uterine Contraction Induced by Oxytocin

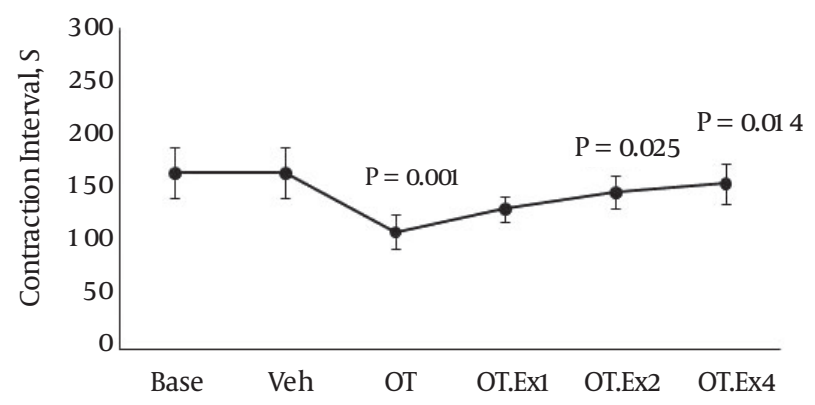

Oxytocin increased the frequency of uterine contraction while it reduced significantly by $R$. damascena ( 2 and $4 \mathrm{mg} / \mathrm{mL}$ ). Veh; Vehicle, OT: oxytocin, OT.Ex1, OT.Ex2, and OT.Ex4 are the oxytocin plus $R$. damascena extracts with the concentrations of 1 , 2 and $4 \mathrm{mg} / \mathrm{mL}, \mathrm{P}=0.001$ compared to vehicle and $\mathrm{P}=0.025$ and 0.014 compared to oxytocin.

4.3. The Effect of $R$. damascena on the Duration of Uterine Smooth Muscle Contraction in the Absence and Presence of Oxytocin

In the beginning, the basal uterine contractions were recorded. Then, either vehicle or alcoholic extract of $R$. damascena was added to the organ bath in stepwise increasing concentrations of 1,2 , and $4 \mathrm{mg} / \mathrm{mL}$ with a 1minute interval. Neither vehicle nor extracts had significant effects on the duration of contraction (Figure 6).

Oxytocin increased the duration of contraction in uterine smooth muscle, but it has not any significant difference with basal duration. Extracts of $R$. damascena were added to the chamber solution in stepwise increasing concentrations of 1,2 and $4 \mathrm{mg} / \mathrm{mL}$ with a 1-minute interval. The Rose extract had no significant effect on the duration of uterine contractions induced by oxytocin (Figure 7). 
Figure 6. The Effect of R. damascena Extracts on the Duration of Contraction in the Uterus

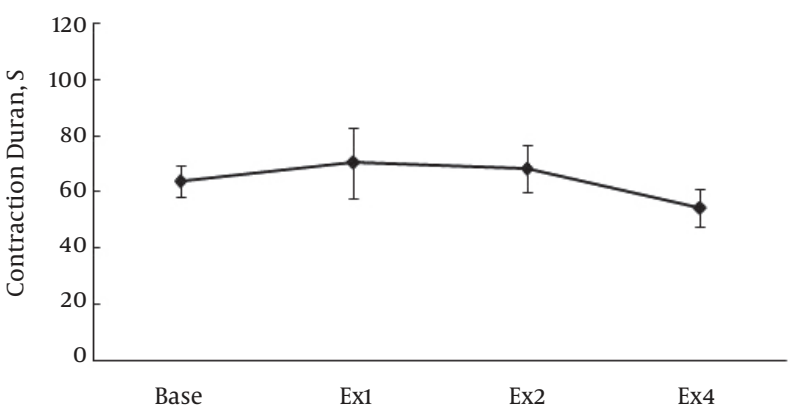

R. damascena had no significant effect on duration of uterine contraction. Ex1, Ex2, and Ex4 are the R. damascena extracts with the concentrations of 1,2 and $4 \mathrm{mg} / \mathrm{mL}$

Figure 7. The effect of R. damascena extracts on the duration of contraction in uterus induced by oxytocin

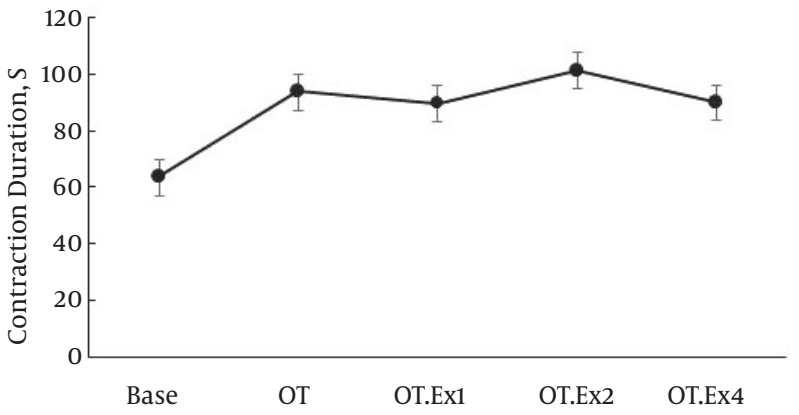

It did not show any significant effect on the duration of contraction. OT: oxytocin, OT.Ex1, OT.Ex2, and OT.Ex4 are oxytocin plus $R$. damascena extracts with the concentrations of 1,2 and $4 \mathrm{mg} / \mathrm{mL}$

\section{Discussion}

Our results showed that ethanol extract of $R$. damascena at a concentration of $4 \mathrm{mg}$, reducedbasal and oxytocin induced contractions in uterine horn. Also $R$. damascena extracts at $4 \mathrm{mg} / \mathrm{ml}$ concentration, reduced the basal frequency of uterine contraction and those contractions induced by oxytocin, but did not show significant effects ontheduration of contractions. No study had previously been performed on the effect of $R$. damascena on the tension, duration and the intervals between contractions (contraction frequency) in the uterus of rat. However, in few researches the effect of R.damascena leaf or flower extraction on uterine contraction or pain has been studied. Sedighi and colleague reported that hydro-alcoholic extract of $R$. damascena Mill leaf $(0.5,0.75$ and $0.75 \mu \mathrm{g} / \mathrm{ml})$, induced contraction in the rat's trachea, aorta and uterus smooth muscle dose dependently (15). Our results was in contrast to that report, which might be due to the consequences of dif- ferences in the types of plant extracts, methods of work or especially in the concentrations of extracts had been used in these studies. The extract may have produced different effects with low or high concentrations. Sadraei et al. had also reported the various effects of $R$. damascena extract on ileum contractions induced by $\mathrm{KCl}$ and Ach. Rosa damascena $(10-100 \mathrm{mg} / \mathrm{ml})$ induced contraction in rat isolated ileum, while at $1 \mathrm{mg} / \mathrm{ml}$ concentration it had relaxant effect. That is might be because of the presence of different components in the extract (14). Smooth muscle relaxation requires a decreased intracellular calcium concentration and increased myosin phosphatase activity, both mediate through a detailed intracellular pathway involving cAMP, cGMP and calcium channels blockers (18). Inhibitory effect of $R$. damascena extract on uterine contraction maybe produced through the interaction with these processes. For instance, it has been reported that $R$. damascena has potent relaxant effect on tracheal smooth muscle of guinea pigs ( 11) that may have been produced by $\beta$-adrenergic receptors stimulation, inhibition of histamine $(\mathrm{H} 1)$ receptors or calcium channel blockage $(10,11)$. Moreover ethanolic extract of $R$. damascena has a relatively potent inotropic and chronotropic effect on isolated guinea-pig heart that probably is mediated by $\beta$-adrenergic receptor stimulation (19). Several components were isolated from $R$. damascena including terpenes, glycosides, flavonoids, and anthocyanins, myrcene, vitamin $\mathrm{C}$, kaempferol and quarcetin. Flowers also contain a bitter principle, tanning matter, fatty oil and organic acids (12, 20-24). Furthermore analyses of rose absolute extract show that phenyl ethylalcohol, citrenellol, nonadecane and geraniol, ethanol, and heneicosane are the main constituents (25). The medicinal functions of Rosaceae are partly attributed to the phenolics compound which have antioxidants, freeradical scavengers, anti-cancer, anti-inflammatory, antimutagenic, and anti-depressant effects (26). Other functions of $R$. damascena have been reported. As Sedighi et al results indicated that $R$. damascena Mill decreased ileum contractions induced by $\mathrm{KCl}$ dose-dependently probably through stimulating the $\beta$-adrenergic receptors and inhibition of voltage-dependent calcium channels in the rat (15). The basic phasic nature of uterine contraction is critically dependent on calcium influx and on membrane potential (27-29) and R. damascena may affect calcium channels. Cyclic AMP relaxant effect on uterine smooth muscle is mediated through inhibition of calcium mobilization and the contractile apparatus $(30,31)$. In myometrium adenylyl cyclase's activity is induced by agonists like catecholamines and prostaglandins operating through $\beta 2$ adrenoceptor and prostaglandin E2 receptor (32). So cyclicAMP signaling pathways may be the other possible way affected by R. damascena on uterine relaxant effect. Resting 
membrane potential is largely established by the activation of K channels of the smooth muscles. There are many different types of $\mathrm{K}$ channels and their isoforms. The main effect of increased K conductance is to decrease excitability (33). There is not any report on the effect of $R$. damascena on K channels, and unfortunately we did not study it, this one of the failure in this study, which remains for further clarifications.

\subsection{Conclusion}

Uterine smooth muscle is involved in pathological conditions such as dysmenorrhea. Clearly, factors affecting the uterine contractions can be effective in the treatment or controling this problem. In this study, $R$. damascena reduced tension and frequency of uterine contraction, which it may also serve to relieve dysmenorrhea and premature labor, which needs further studies for more clarification.

\section{Acknowledgments}

This study was supported by a grant (No. 891) from Semnan University of Medical Sciences, Semnan, Iran. We are grateful to vice chancellor for physiology research center, heads of departments of physiology and organization of promotion, education, and agricultural research, Semnan, for their support. The results described in this paper were taken out from a student project.

\section{Footnotes}

Conflict of Interests: The authors declare that they have no conflict of interest related to this manuscript.

Funding/Support: Vice chancellor for research centers of Semnan University of Medical Sciences, Semnan, Iran (Grant No. 891).

\section{References}

1. Calixto JB. Efficacy, safety, quality control, marketing and regulatory guidelines for herbal medicines (phytotherapeutic agents). Braz JMed Biol Res. 2000;33(2):179-89. doi:10.1590/S0100-879X2000000200004. [PubMed: 10657057].

2. Nasri H, Shirzad H. Toxicity and safety of medicinal plants. J HerbMed Pharmacol. 2013;2(2):21-2.

3. Nyeem M, Alam M, Awal M, Mostofa M, Uddin S, Islam N, et al. Cns depressant effect of the crude ethanolic extract of the flowering tops of Rosa damascena. Iran J Pharm Res. 2006;5(2):171-4.

4. Ramezani R, Moghimi A, Rakhshandeh H, Ejtehadi H, Kheirabadi M. The effect of Rosa damascena essential oil on the amygdala electrical kindling seizures in rat. Pak J Biol Sci. 2008;11(5):746-51. doi: 10.3923/pjbs.2008.746.751. [PubMed: 18819571]

5. Kempuraj D, Madhappan B, Christodoulou S, Boucher W, Cao J, Papadopoulou N, et al. Flavonols inhibit proinflammatory mediator release, intracellular calcium ion levels and protein kinase $C$ theta phosphorylation in human mast cells. BrJ Pharmacol. 2005;145(7):934-44. doi: 10.1038/sj.bjp.0706246. [PubMed: 15912140].
6. Rakhshandah H, Hosseini M, Dolati K. Hypnotic effect of Rosa damascena in mice. Iran J Pharm Res. 2010:181-5.

7. Hongratanaworakit T. Relaxing effect of rose oil on humans. Nat Prod Commun. 2009;4(2):291-6. [PubMed: 19370942].

8. özkan G, Sagdiç O, Baydar NG, Baydar H. Note: Antioxidant and antibacterial activities of Rosa damascena flower extracts. Food Sci Techno Inter. 2016;10(4):277-81. doi: 10.1177/1082013204045882.

9. Talib WH, Mahasneh AM. Antimicrobial, cytotoxicity and phytochemical screening of Jordanian plants used in traditional medicine. Molecules. 2010;15(3):1811-24. doi: 10.3390/molecules15031811. [PubMed: 20336015].

10. Shafei MN, Rakhshandah H, Boskabady MH. Antitussive effect of Rosa damascena in guinea pigs. Iran J Pharm Res. 2010;2(4):231-4.

11. Boskabady MH, Kiani S, Rakhshandah H. Relaxant effects of Rosa damascena on guinea pig tracheal chains and its possible mechanism(s). J Ethnopharmacol. 2006;106(3):377-82. doi: 10.1016/j.jep.2006.01.013. [PubMed: 16504433].

12. Rakhshandah H, Boskabady MH, Mossavi Z, Gholami M, Saberi Z. The Differences in the relaxant effects of different fractions of Rosa damascena on guinea pig tracheal smooth muscle. Iran J Basic Med Sci. 2010;13(3):126-32.

13. Kwon EK, Lee DY, Lee H, Kim DO, Baek NI, Kim YE, et al. Flavonoids from the buds of Rosa damascena inhibit the activity of 3-hydroxy-3 methylglutaryl-coenzyme a reductase and angiotensin I-converting enzyme. J Agric Food Chem. 2010;58(2):882-6. doi: 10.1021/jf903515f. [PubMed: 20038104].

14. Sadraei H, Asghari G, Emami S. Effect of Rosa damascena Mill. flower extract on rat ileum. Res Pharm Sci. 2013;8(4):277-84. [PubMed: 24082897]

15. Sedighi M, Rafieian-Kopaei M, Noori-Ahmadabadi M, Godarzi I, Baradaran A. In Vitro Impact of Hydro-alcoholic Extract of Rosa damascena Mill. on Rat Ileum Contractions and the Mechanisms Involved. Int J Prev Med. 2014;5(6):767-75. [PubMed: 25013697].

16. Sedighi M, Rafieiankopaei M, Noori Ahmadabadi M, Tadi M, Heidari R. Effect of hydro-alcoholic extract of rosa damascena mill leaf on smooth muscle contraction [In Persian]. Babol Univ Med Sci. 2014;16(11):36-43.

17. Bani S, Hasanpour S, Mousavi Z, Mostafa Garehbaghi P, Gojazadeh M. The Effect of Rosa Damascena Extract on Primary Dysmenorrhea: A Double-blind Cross-over Clinical Trial. Iran Red Crescent Med J. 2014;16(1):e14643. doi: 10.5812/ircmj.14643. [PubMed: 24719710].

18. Webb RC. Smooth muscle contraction and relaxation. Adv Physiol Educ. 2003;27(1-4):201-6. [PubMed:14627618].

19. Boskabady MH, Vatanprast A, Parsee H, Ghasemzadeh M. Effect of aqueous-ethanolic extract from Rosa damascena on guinea pig isolated heart. Iran J Bas Med Sci. 2011;14(2):116-21.

20. Oka N, Ikegami A, Ohki M, Sakata K, Yagi A, Watanabe N. Citronellyl disaccharide glycoside as an aroma precursor from rose flowers. Phy tochem. 1998;47(8):1527-9. doi:10.1016/s0031-9422(97)00526-8.

21. Knapp H, Straubinger M, Fornari S, Oka N, Watanabe N, Winterhalter P. (S)-3,7-Dimethyl-5-octene-1,7-diol and related oxygenated monoterpenoids from petals of rosadamascena mill.JAgri Food Chem. 1998;46(5):1966-70. doi: 10.1021/jf970987x.

22. Schiber A, Mihalev K, Berardini N, Mollov P, Carle R. Flavonol glycosides from distilled petals of Rosa damascena Mill. Z Natur forsch C. 2005;60(5-6):379-84. doi: 10.1515/znc-2005-5-602. [PubMed 16042335]

23. Kumar N, Singh B, Kaul VK. Flavonoids from Rosa damascena mill. Nat Prod Commun. 2006;1(8):623-6.

24. Ulusoy S, Bosgelmez-Tinaz G, Secilmis-Canbay H. Tocopherol, carotene, phenolic contents and antibacterial properties of rose essential oil, hydrosol and absolute. Curr Microbiol. 2009;59(5):554-8. doi: 10.1007/s00284-009-9475-y. [PubMed: 19688375]. 
25. Ng TB, Liu F, Wang ZT. Antioxidative activity of natural products from plants.Life Sci. 2000;66(8):709-23. doi:10.1016/S0024-3205(99)006426. [PubMed: 10680579].

26. Butterweck V, Jurgenliemk G, Nahrstedt A, Winterhoff H. Flavonoids from Hypericum perforatum show antidepressant activity in the forced swimming test. Planta Med. 2000;66(1):3-6. doi: 10.1055/s2000-11119. [PubMed:10705724].

27. Wray S, Jones K, Kupittayanant S, Li Y, Matthew A, Monir-Bishty E, et al. Calcium signaling and uterine contractility. J Soc Gynecol Investig. 2003;10(5):252-64. doi: 10.1016/S1071-5576(03)00089-3. [PubMed 12853086].

28. Wray S. Uterine contraction and physiological mechanisms of modulation. Am J Physiol. 1993;264(1 Pt 1):C1-18. [PubMed: 8430759].

29. Sanborn BM. Relationship of ion channel activity to control of myometrial calcium. J Soc Gynecol Investig. 2000;7(1):4-11. doi:
10.1177/107155760000700103. [PubMed: 10732311].

30. Yuan W, Lopez Bernal A. Cyclic AMP signalling pathways in the regulation of uterine relaxation. BMC Pregnancy Childbirth. 2007;7 Suppl 1:S10. doi: 10.1186/1471-2393-7-S1-S10. [PubMed: 17570154].

31. Sanborn BM. Hormones and calcium: mechanisms controlling uterine smooth muscle contractile activity. The Litchfield Lecture. Exp Physiol. 2001;86(2):223-37. doi: 10.1113/eph8602179. [PubMed: 11429639].

32. Lopez Bernal A, Europe-Finner GN, Phaneuf S, Watson SP. Preterm labour: a pharmacological challenge. Trends Pharmacol Sci. 1995;16(4):129-33. doi: 10.1016/S0165-6147(00)89000-8. [PubMed: 7610498].

33. Parkington HC, Coleman HA. Ionic mechanisms underlying action potentials in myometrium. Clin Exp Pharmacol Physiol. 1988;15(9):65765. doi: 10.1111/j.1440-1681.1988.tb01125.x. [PubMed: 2856064]. 